\title{
Pemanfaatan Cangkang Telur dan Sekam Padi Sebagai Bioadsorben Metilen Biru pada Limbah Tekstil
}

\author{
Naning Citra Lestari ${ }^{*}$, Ilham Budiawan ${ }^{1}$, Ahmad Muhammad Fuadi ${ }^{1}$ \\ 1Jurusan Teknik Kimia, Fakultas Teknik, Universitas Muhammadiyah Surakarta, Jawa Tengah, \\ Indonesia
}

Corresponding author:

Naning Citra Lestari

d500170110@student.ums.ac.id

Received: February 2021

Accepted: March 2021

Published: March 2021

(CNaning Citra Lestari et al. This is an open-access article distributed under the terms of the Creative Commons Attribution License, which permits unrestricted use, distribution, and reproduction in any medium, provided the original author and source are credited.

\begin{abstract}
The textile industry in Indonesia has increased since the 1980s. From the nonoil and gas sector, the textile industry is the government's largest source of income. In addition to its impressive growth, about $10-15 \%$ of the used textile dyestuff is wasted at the dyeing process can exceed the maximum Chemical Oxygen Demand level of $150 \mathrm{mg} / \mathrm{L}$. Synthetic dyes contain carcinogenic ingredients that can harm the environment and aquatic biota. The alternative for handling the dye waste is the adsorption method using bio adsorbent from a mixture of chicken eggshells and rice husk ash. Both have the potential to be used as adsorbents because they have an active site, abundant amounts, and are economical. This study was to determine the effect of the process variables of the adsorbent mass ratio, contact time, and $\mathrm{pH}$ on the adsorption capacity of methylene blue using a mixture of eggshells and rice husk ash with the UV-Vis Spectrophotometer analysis method. The results showed that the optimal conditions for the adsorption of $20 \mathrm{ppm}$ methylene blue were 0.2:0.8 gram of adsorbent ratio, 80 minutes, and $\mathrm{pH}$ of 3 . The adsorption capacity obtained was $98.817 \%$, reduced the methylene blue concentration to $0.237 \mathrm{ppm}$.
\end{abstract}

Keywords: adsorption, synthetic dyes, rice husks, eggshells, bioadsorbent

\section{Pendahuluan}

Industri tekstil di Indonesia telah mengalami peningkatan tepatnya sejak 1980-an. Dari sektor non-migas, industri tekstil menjadi sumber penghasilan terbesar pemerintah dan terbesar ketiga setelah minyak bumi dan gas alam[1]. Berdasarkan data Statistik Departemen Perdagangan dan Perindustrian pada tahun 1998, industri tekstil telah menyumbangkan sekitar 20\% dari ekspor non-migas Indonesia. Di samping pertumbuhannya yang mengagumkan, masih terdapat berbagai masalah seperti tingginya tingkat pencemaran limbah cair sisa proses pewarnaan.
Terdapat lebih dari 700,000 ton bahan pewarna yang diproduksi tiap tahun dengan 10,000 jenis pewarna ${ }^{[2]}$. Pada tahap pencelupan, dihasilkan sekitar $6 \%$ garam dan $24 \%$ zat warna yang digunakan pada proses pewarnaan, masuk ke perairan menjadi limbah cair. Timbulnya warna tekstil tersebut akibat keberadaan gugus kromofor[3], seperti gugus vinil $(-\mathrm{C}=\mathrm{C}-)^{[}$, karbonil $(-\mathrm{C}=\mathrm{O})$, azo $(-\mathrm{N}=\mathrm{N}-)$, serta nitro ($\mathrm{NO}_{2}$ ). Selain itu terdapat pula gugus auksokrom seperti $-\mathrm{OH},-\mathrm{SO}_{3} \mathrm{H},-\mathrm{NH}_{2}$, dan $-\mathrm{COOH}^{44}$. Dalam pewarna tekstil, senyawa azo memiliki jumlah yang paling banyak yaitu sekitar 60$70 \%$ [5]. 
Kadar maksimal Chemical Oxygen Demand (COD) yang merupakan salah satu parameter pada mutu air berdasarkan KepMen LH No. 51/MENLH/10/1995 sebesar $150 \mathrm{mg} / \mathrm{L}$. Nilai tersebut jauh di bawah nilai COD dari limbah tekstil pada umumnya atau sekitar 150-12,000 $\mathrm{mg} / \mathrm{L}^{[6]}$. Dampak lingkungan yang disebabkan oleh pewarna sintetik tersebut seperti tingginya BOD dan COD, mutagenik, karsiogenik, dan toksisitas $^{[7]}$. Degradasi pewarna, terutama pewarna reaktif sulit, karena strukturnya yang kompleks, kelarutan dalam air, dan sifat sintetisnya ${ }^{[8]}$.

Senyawa metilen biru $\left(\left(\mathrm{C}_{16} \mathrm{H}_{18} \mathrm{~N}_{3} \mathrm{~S}\right)^{+}(\mathrm{Cl})^{-}\right)$ merupakan salah satu zat warna sintetik biasanya dibuat sebagai garam kloridanya, agar memudahkan untuk larut ke dalam air sehingga dapat terionisasi membentuk ion $\mathrm{C}_{16} \mathrm{H}_{18} \mathrm{~N}_{3} \mathrm{~S}^{+}$dan ion $\mathrm{Cl}$. Dengan terbentuknya kation tersebut berpotensi untuk terikat pada suatu adsorben yang memiliki gugus-gugus bermuatan negatif, sehingga memungkinkan proses adsorpsi terjadi, baik secara fisika maupun kimia[ ${ }^{[9]}$.

Adsorpsi merupakan salah satu metode untuk menurunkan konsentrasi zat pewarna terlarut yang murah serta efektif. Di antara jenis adsorben, karbon aktif banyak digunakan karena memiliki kapasitas penjerapan yang tinggi. Penggunaannya cukup luas dalam dunia industri, seperti pembersihan air limbah industri, penghilangan bau, pengolahan LNG, pemurnian gas, dan katalisator ${ }^{[10]}$. Namun, adsorben karbon aktif tergolong mahal karena proses aktivasi dan sulitnya penguraian karbon aktif yang telah digunakan[8].

Salah satu sumber pembuatan adsorben yang potensial sebagai pengganti karbon aktif yaitu cangkang telur ayam dan sekam padi. Komponen penyusun cangkang telur yaitu $\mathrm{CaCO}_{3}(98.41 \%)$ dalam bentuk kristal, $\mathrm{Ca}_{3}\left(\mathrm{PO}_{4}\right)_{2}$ $(0.75 \%)$, dan $\mathrm{MgCO}_{3}$ (0.84\%). Material ini berpeluang untuk dimanfaatkan sebagai adsorben karena mempunyai sekitar 10,00020,000 pori-pori sehingga dapat menjerap suatu zat terlarut ${ }^{[11]}$. Sedangkan kandungan dari abu sekam padi yaitu silika sekitar $87 \%-97 \%$ dari berat kering yang dibakar dengan pembakaran sempurna ${ }^{[12]}$.
Abu sekam padi dapat dimanfaatkan sebagai adsorben dikarenakan material tersebut memiliki pori-pori serta memiliki gugus aktif silanol (Si-OH) dan siloksan (Si-O-Si) ${ }^{[13]}$.

Cangkang telur ini sebelumnya telah digunakan sebagai material penjerap untuk penurunan kadar logam pada limbah cair hasil industri elektroplating, peningkatan kualitas minyak jelantah, serta pemisahan kromium ${ }^{[13]}$. Adapun pemanfaatan sekam padi sebagai adsorben dari ion logam berat terlarut ${ }^{[14]}$. Hasil dari studi literatur menunjukkan baik sekam padi maupun cangkang telur ayam memiliki potensi untuk dikembangkan menjadi adsorben zat warna tekstil karena jumlahnya melimpah, memiliki gugus aktif, dan ekonomis.

\section{Metode Penelitian}

\section{Bahan kimia}

Penelitian ini menggunakan bahan-bahan seperti aquades, cangkang telur, sekam padi, metilen biru (Merck), $\mathrm{HCl}$ (Merck, 37\%), dan $\mathrm{NaOH}$ (Merck, 99\%).

\section{Peralatan}

Penelitian ini menggunakan peralatan seperti peralatan gelas, oven, hotplate, furnace, magnetic stirer, mortar, cawan porselin, neraca analitik, ayakan 100 mesh, spektrofotometer GENESYS $10 \mathrm{UV}-\mathrm{Vis}$.

\section{Prosedur penelitian}

\section{Persiapan abu sekam padi}

Sekam padi sebanyak $200 \mathrm{~g}$ dalam cawan pengabuan dimasukkan dalam furnace pada suhu $600{ }^{\circ} \mathrm{C}$ selama 4 jam hingga seluruhnya menjadi abu. Setelah itu, sampel disaring dengan ayakan 100 mesh.

\section{Persiapan cangkang telur}

Cangkang telur ayam ras sebanyak $100 \mathrm{~g}$ dipisahkan dari membrannya lalu dicuci bersih. Keringkan di bawah sinar matahari, dan dihaluskan menggunakan mortar. Setelah itu, sampel disaring dengan ayakan 100 mesh. 
Proses aktivasi dan persiapan campuran adsorben

Abu sekam padi dan cangkang telur secara terpisah direndam menggunakan $\mathrm{HCl} \quad 0.1 \mathrm{M}$ selama 90 menit. Setelah itu, disaring dengan kertas saring dan dibilas menggunakan aquades hingga $\mathrm{pH}$ netral. Lalu, dilakukan aktivasi pori-pori adsorben dengan dioven selama 1.5 jam pada $105^{\circ} \mathrm{C}$.

\section{Pembuatan larutan induk metilen biru}

Metilen biru dengan konsentrasi 1000 ppm dibuat dengan melarutkan $100 \mathrm{~g}$ metilen biru dalam $100 \mathrm{~mL}$ aquades. Lalu larutan dimasukkan dalam labu ukur 100 mL.

\section{Pembuatan larutan standar metilen biru}

Pembuatan larutan metilen biru 100 ppm dilakukan dengan mengambil larutan induk metilen biru $5 \mathrm{~mL}$ lalu diencerkan ke labu ukur 50 mL. Dari larutan tersebut diencerkan kembali menjadi konsentrasi yang lebih kecil yaitu 1, 2, 3, 4, 5, 6, dan 7 ppm dalam $50 \mathrm{~mL}$.

\section{Penentuan panjang gelombang optimum metilen biru}

Sebanyak $50 \mathrm{~mL}$ larutan metilen biru 1 ppm diukur panjang gelombangnya menggunakan spektrofotometer UV-Vis pada 600-700 nm. Hasil dari absorbansi terbesar ditetapkan sebagai panjang gelombang optimum.

\section{Adsorpsi metilen biru}

Adsorpsi zat metilen biru dilakukan pada variasi rasio massa adsorben, waktu kontak, dan $\mathrm{pH}$ adsorbat menggunakan proses pengadukan pada hotplate dengan suhu ruang. Ukur absorbansi larutan metilen biru pada panjang gelombang optimum menggunakan Spektrofotometer UV-Vis. Setelah berjalannya waktu yang telah ditentukan, larutan kemudian disaring menggunakan kertas saring.

\section{Penentuan rasio adsorben optimum}

Siapkan sampel adsorben $1 \mathrm{~g}$ dengan rasio massa cangkang telur: abu sekam padi $0: 1$; 0.1:0.9; 0.2:0.8; 0.3:0.7; 0.4:0.6; 0.5:0.5; 0.6:0.4;
0.7:0.3; $\quad 0.8: 0.2 ; \quad 0.9: 0.1 ; \quad 1: 0 \quad$ g. Kemudian masukkan $50 \mathrm{~mL}$ larutan metilen biru 20 ppm ke gelas beker $250 \mathrm{~mL}$. pH larutan sesuai dengan $\mathrm{pH}$ pelarut aquades. Proses adsorpsi dilakukan selama 60 menit.

\section{Penentuan waktu kontak optimum}

Hasil rasio adsorben optimum digunakan untuk menentukan kapasitas adsorpsi optimum dengan variasi waktu 20, 30, 40, 60, 80 menit pada $\mathrm{pH}$ yang sama dengan $\mathrm{pH}$ aquades.

\section{Penentuan pH optimum}

Hasil rasio adsorben dan waktu kontak optimum digunakan untuk menentukan $\mathrm{pH}$ optimum dengan variasi $\mathrm{pH} 3 ; 5 ; 7 ; 9 ; 11$.

\section{Perhitungan daya adsorpsi}

Guna mengetahui efektivitas kombinasi cangkang telur dan sekam padi sebagai adsorben, pengukuran absorbansi diperlukan pada larutan metilen biru sesudah proses adsorpsi menggunakan Spektrofotometer UVVis. Hasil pengukuran digunakan untuk menghitung kapasitas dan daya adsorpsi. Kapasitas adsorpsi dapat diperoleh melalui persamaan (1):

$\mathrm{q}=\frac{\mathrm{V}\left(\mathrm{C}_{\mathrm{o}}-\mathrm{C}_{\mathrm{e}}\right)}{\mathrm{m}}$

Keterangan:

$\mathrm{q}=$ kapasitas adsorpsi $(\mathrm{mg} / \mathrm{g})$

$\mathrm{m}$ = massa adsorben $(\mathrm{g})$

$\mathrm{V}=$ volume larutan metilen biru (L)

$\mathrm{C}_{\mathrm{o}}=$ konsentrasi larutan metilen biru sebelum adsorpsi (mg/L)

$\mathrm{C}_{\mathrm{e}}=$ konsentrasi larutan metilen biru setelah adsorpsi (mg/L)

Sedangkan daya adsorpsi diperoleh menggunakan persamaan (2):

$\mathrm{D} \%=\frac{\mathrm{C}_{\mathrm{o}}-\mathrm{C}_{\mathrm{e}}}{\mathrm{C}_{0}} \times 100 \%$

Keterangan:

$\mathrm{D} \%$ = daya adsorpsi $(\%)$ 


\section{Hasil dan Diskusi}

Penentuan panjang gelombang maksimum diukur dari nilai absorbansi terbesar pada rentang 600-700 nm menggunakan spektrofotometer UV-Vis.

Dari Gambar 1 menunjukkan bahwa nilai absorbansi terbesar berada pada $666 \mathrm{~nm}$. Panjang gelombang ini kemudian digunakan untuk pembuatan kurva standar dan pengukuran absorbansi setelah proses adsorpsi.

Kurva standar digunakan untuk mengetahui konsentrasi larutan setelah dilakukannya proses adsorpsi. Gambar 2 menunjukkan bahwa kurva standar tersebut memiliki korelasi 0.9961 Sehingga kurva standar ini memiliki regresi linear di atas nilai yang ditetapkan atau sebesar
$0.99 \geq 0.005$ untuk menunjukkan kelayakan suatu analisis.

\section{Analisis FTIR}

Pengamatan gugus fungsi cangkang telur dan sekam padi diperlukan sebelum dilakukannya proses adsorpsi menggunakan Spektrofotometer FTIR. Pada pengamatan yang dilakukan Haqiqi (2018), menunjukkan gugus fungsi karbonat cangkang telur ditemukan pada bilangan gelombang 1413.87-1427.37 $\mathrm{cm}^{-1}$. Sedangkan gugus fungsi $-\mathrm{OH}$ pada sekam padi muncul pada bilangan gelombang $3367.82 \mathrm{~cm}^{-1}$ dan $-\mathrm{C}=\mathrm{O}$ pada $1649.19 \mathrm{~cm}^{-1}$. Kombinasi dari kedua bahan tersebut menunjukkan adanya gugus karbonat, gugus hidroksil $(-\mathrm{OH})$, dan gugus karboksil $(-\mathrm{C}=\mathrm{O})^{[15]}$.

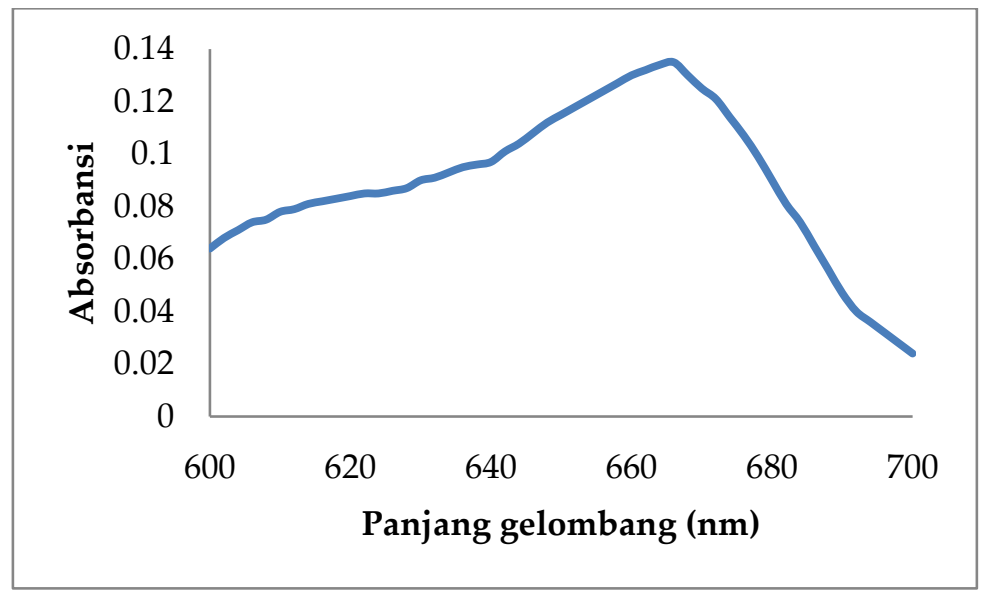

Gambar 1. Penentuan panjang gelombang optimum.

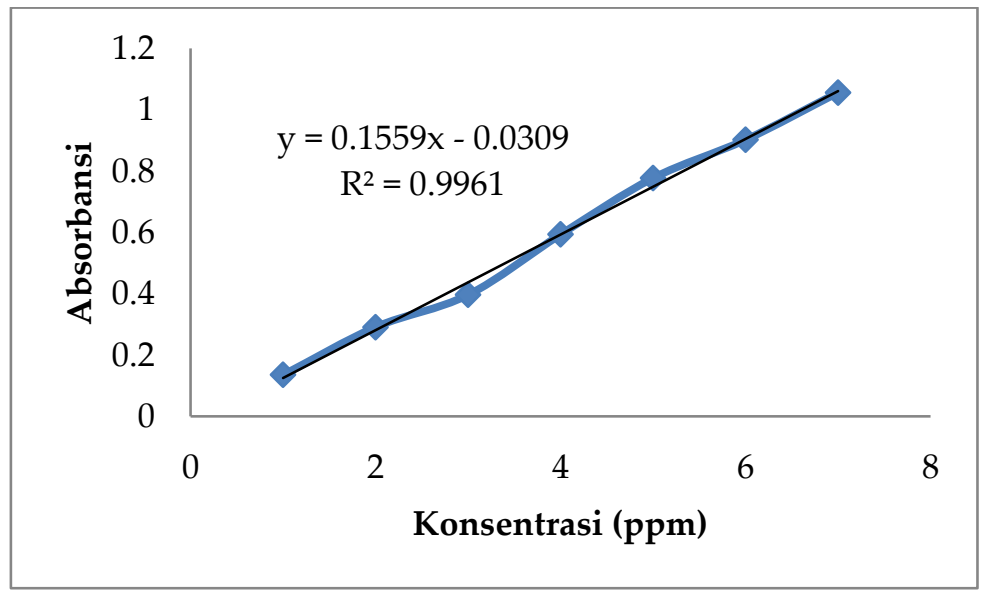

Gambar 2. Kurva standar larutan metilen biru 1 ppm. 


\section{Analisis SEM}

Analisis SEM dilakukan untuk mengetahui morfologi suatu adsorben. Penelitian yang dilakukan oleh Pardede (2020) menujukkan setelah dilakukannya aktivasi sebelum proses adsorpsi, terlihat jarak antar partikel yang berongga, dimana ukuran partikel ini dipengaruhi oleh energi kinetik yang meningkat akibat pengaruh suhu sehingga terjadi diaglomerasi[16].

Sedangkan analisa yang dilakukan Wardalia (2016) menunjukkan setelah dilakukan aktivasi, hidrokarbon penyumbat permukaan adsorben menjadi terangkat. Hal ini dapat meningkatkan jumlah zat terlarut yang dijerap. Oleh karena itu proses aktivasi dan ukuran mesh sangat berpengaruh terhadap efisiensi adsorpsi ${ }^{[14]}$. Setelah dilakukannya proses adsorpsi menunjukkan adanya penambahan volume partikel akibat terjerapnya zat terlarut ke permukaan adsorben ${ }^{[17]}$.

\section{Pengaruh rasio massa adsorben}

Pengaruh massa adsorben terhadap daya adsorpsi dapat dilihat pada Tabel 1 .
Tabel 1 menunjukkan efisiensi penjerapan larutan metilen biru dengan massa adsorben $1 \mathrm{~g}$ sekam padi lebih tinggi daripada adsorben cangkang telur dengan massa yang sama. Pada abu sekam padi, terdapat pola serapan silika yaitu gugus aktif $\mathrm{Si}-\mathrm{O}-\mathrm{Si}$ dan $\mathrm{Si}-\mathrm{OH}^{[18]}$. Di samping itu, komponen terbesar penyusun cangkang telur yaitu $\mathrm{CaCO}_{3}$, dimana senyawa ini termasuk dalam golongan adsorben polar ${ }^{[11]}$. Kedua material ini juga memiliki pori-pori yang dapat memperbesar luas permukaannya.

Daya adsorpsi metilen biru meningkat seiring bertambahnya massa adsorben sehingga jumlah sisi aktif pada permukaan adsorben makin bertambah. Namun, pada kondisi tertentu daya adsorpsi akan konstan atau bahkan dapat menurun dikarenakan adsorben telah mengalami kejenuhan akibat dari menurunnya jumlah sisi aktif[19]. Penurunan tersebut ditunjukkan pada rasio massa cangkang telur dibanding abu sekam padi 0.3:0.7 g hingga 1:0 gram. Rasio massa adsorben optimum antara cangkang telur dengan abu sekam padi yaitu 0.2:0.8 g dimana presentase zat teradsorpsinya mencapai $98.400 \%$.

Tabel 1. Pengaruh rasio massa adsorben terhadap daya adsorpsi

\begin{tabular}{|c|c|c|c|c|c|c|c|c|}
\hline $\begin{array}{c}\text { Rasio } \\
\text { adsorben } \\
\text { [CT:SP] } \\
\text { (g) }\end{array}$ & $\begin{array}{c}\text { Volume } \\
\text { larutan } \\
(\mathrm{mL})\end{array}$ & $\begin{array}{l}\text { Konsentrasi } \\
\text { metilen biru } \\
\quad(\mathrm{ppm})\end{array}$ & $\mathrm{pH}$ & $\begin{array}{l}\text { Waktu } \\
\text { (menit) }\end{array}$ & Absorbansi & $\begin{array}{c}\mathrm{C}_{\mathrm{e}} \\
(\mathrm{mg} / \mathrm{L})\end{array}$ & $\begin{array}{c}\mathrm{q}_{\mathrm{e}}(\mathrm{mg} / \mathrm{g} \\
\text { adsorben) }\end{array}$ & $\mathrm{D} \%$ \\
\hline 0.0:0.1 & & & & & 0.081 & 0.718 & 964.112 & 96.411 \\
\hline $0.1: 0.9$ & & & & & 0.044 & 0.480 & 975.978 & 97.598 \\
\hline $0.2: 0.8$ & & & & & 0.019 & 0.320 & 983.996 & 98.400 \\
\hline 0.3:0.7 & & & & & 0.028 & 0.378 & 981.110 & 98.111 \\
\hline 0.4:0.6 & & & & & 0.037 & 0.436 & 978.223 & 97.822 \\
\hline 0.5:0.5 & 50 & 20 & 8.3 & 60 & 0.047 & 0.500 & 975.016 & 97.502 \\
\hline 0.6:0.4 & & & & & 0.053 & 0.538 & 973.092 & 97.309 \\
\hline $0.7: 0.3$ & & & & & 0.066 & 0.622 & 968.922 & 96.892 \\
\hline $0.8: 0.2$ & & & & & 0.073 & 0.666 & 966.677 & 96.668 \\
\hline 0.9:0.1 & & & & & 0.114 & 0.929 & 953.528 & 95.353 \\
\hline 1.0:0.0 & & & & & 0.442 & 3.033 & 848.332 & 84.833 \\
\hline
\end{tabular}


Penelitian sebelumnya yang dilakukan oleh Kristiyani dkk. (2012) yang memanfaatkan abu sekam padi sebagai penurun kadar $\mathrm{Pb}^{2+}$ pada air sumur. Hasil menyatakan bahwa semakin bertambahnya massa adsorben akan maka zat terlarut dan terjerap semakin meningkat ${ }^{[20] .}$

\section{Pengaruh waktu kontak}

Pengaruh waktu kontak terhadap daya adsorpsi larutan metilen biru ditunjukkan pada Tabel 2. Tabel 2 menunjukkan pertambahan waktu mempengaruhi meningkatnya konsentrasi metilen biru yang terjerap. Pada proses ini juga dibantu proses pengadukan dengan tujuan untuk meningkatkan kecepatan reaksi sehingga tumbukan yang terjadi akan mempercepat untuk mencapai kondisi setimbang ${ }^{[19]}$. Setelah mencapai waktu adsorpsi optimum, bertambahnya waktu kontak akan mengakibatkan daya adsorpsi menurun. Salah satu faktornya yaitu penggunaan stirer dapat melepaskan partikel metilen biru yang sudah tidak mampu bertahan di permukaan adsorben $^{[13]}$.

Pada penelitian ini, adsorben belum mengalami kejenuhan ditunjukkan dengan kecenderungan grafik yang naik. Namun, kenaikan daya adsorpsi dari menit ke-60 menuju menit ke-80 terlihat tidak signifikan. Hasil menunjukkan waktu terbaik yaitu 80 menit dengan persentase zat metilen biru yang terjerap sebesar $98.496 \%$.
Hasil ini diperkuat dengan hasil penelitian yang dilakukan Nurlaili dkk. (2017) yang menggunakan cangkang telur untuk menjerap zat methyl orange, dimana seiring bertambahnya waktu, zat yang terjerap akan meningkat, kemudian menurun akibat adsorben yang telah jenuh dan adanya proses pengadukan ${ }^{[19]}$.

\section{Pengaruh $\mathrm{pH}$ terhadap daya adsorpsi}

Pengaruh $\mathrm{pH}$ terhadap daya adsorpsi disajikan pada Tabel 3. Tabel 3 menunjukkan konsentrasi zat warna metilen biru yang terjerap menurun seiring dengan bertambahnya derajat keasaman. Daya penjerapan tertinggi diperoleh pada $\mathrm{pH} 3$ dimana metilen biru yang teradsorpsi sebesar $98.817 \%$. Adanya sifat katonik pada metilen biru baru terlihat pada $\mathrm{pH}$ asam. Hal tersebut terjadi karena metilen biru yang terionisasi dalam air akan bermuatan positif $\left(\mathrm{C}_{16} \mathrm{H}_{18} \mathrm{~N}_{3} \mathrm{~S}^{+}\right)$ memungkinkan untuk berikatan dengan permukaan adsorben yang bermuatan negatif sehingga dapat meningkatkan kapasitas dan daya adsorpsi[21]. Sedangkan pada $\mathrm{pH}$ tinggi, permukaan adsorben cangkang telur akan bermuatan negatif sehingga saling menolak dikarenakan metilen biru yang terionisasi menjadi ion negatif $\left(\mathrm{Cl}^{-}\right)^{[19]}$.

Tabel 2. Pengaruh waktu kontak terhadap daya adsorpsi

\begin{tabular}{ccccccccc}
\hline $\begin{array}{c}\text { Waktu } \\
(\text { menit })\end{array}$ & $\begin{array}{c}\text { Konsentrasi } \\
\text { metilen biru } \\
(\mathrm{ppm})\end{array}$ & $\begin{array}{c}\text { Volume } \\
\text { larutan } \\
(\mathrm{mL})\end{array}$ & $\mathrm{pH}$ & $\begin{array}{c}\text { Rasio } \\
\text { adsorben } \\
\text { optimum } \\
(\mathrm{g})\end{array}$ & Absorbansi & $\begin{array}{c}\mathrm{C} \text { e } \\
(\mathrm{mg} / \mathrm{L})\end{array}$ & $\begin{array}{c}\text { qe } \\
\text { adsorben })\end{array}$ & $\begin{array}{c}(\mathrm{mg} / \mathrm{g} \\
\mathrm{D} \%\end{array}$ \\
\hline 20 & & & & 0.040 & 0.455 & 977.261 & 97.726 \\
30 & 50 & 8.3 & $0.2: 0.8$ & 0.028 & 0.378 & 981.110 & 98.111 \\
40 & 20 & & & 0.037 & 0.436 & 978.223 & 97.822 \\
60 & & & & 0.019 & 0.320 & 983.996 & 98.400 \\
80 & & & & & 0.016 & 0.301 & 984.958 & 98.496 \\
\hline
\end{tabular}


Tabel 3. Pengaruh $\mathrm{pH}$ terhadap daya adsorpsi

\begin{tabular}{|c|c|c|c|c|c|c|c|c|}
\hline $\mathrm{pH}$ & $\begin{array}{l}\text { Konsentrasi } \\
\text { metilen biru } \\
\quad(\mathrm{ppm})\end{array}$ & $\begin{array}{c}\text { Volume } \\
\text { larutan } \\
(\mathrm{mL})\end{array}$ & $\begin{array}{c}\text { Rasio } \\
\text { adsorben } \\
\text { optimum } \\
\text { (g) }\end{array}$ & $\begin{array}{l}\text { Waktu } \\
\text { kontak } \\
\text { optimum } \\
\text { (menit) }\end{array}$ & Absorbansi & $\begin{array}{c}\mathrm{Ce}_{\mathrm{e}} \\
(\mathrm{mg} / \mathrm{L})\end{array}$ & $\begin{array}{c}\mathrm{qe}_{\mathrm{e}}(\mathrm{mg} / \mathrm{g} \\
\text { adsorben) }\end{array}$ & $\mathrm{D} \%$ \\
\hline 3 & \multirow{6}{*}{20} & \multirow{6}{*}{50} & \multirow{6}{*}{$0.2: 0.8$} & \multirow{6}{*}{80} & 0.006 & 0.237 & 988.165 & 98.817 \\
\hline 5 & & & & & 0.009 & 0.256 & 987.203 & 98.720 \\
\hline 7 & & & & & 0.012 & 0.275 & 986.241 & 98.624 \\
\hline 8.3 & & & & & 0.016 & 0.301 & 984.958 & 98.496 \\
\hline 9 & & & & & 0.045 & 0.487 & 975.657 & 97.566 \\
\hline 11 & & & & & 0.083 & 0.731 & 963.470 & 96.347 \\
\hline
\end{tabular}

Hasil percobaan ini diperkuat oleh Hadayani dkk. (2015) yang melakukan penjerapan metilen biru menggunakan senyawa xanthat pulpa kopi sebagai adsorben, menyebutkan tingkat adsorpsi akan meningkat seiring dengan penurunan derajat keasaman ${ }^{[22]}$.

\section{Kesimpulan}

Metode adsorpsi merupakan metode alternatif yang dapat digunakan untuk menurunkan kandungan zat warna terlarut dalam limbah cair tekstil. Pada adsorpsi zat warna limbah cair metilen biru dengan adsorben kombinasi dari cangkang telur dan abu sekam padi terbukti mampu menurunkan konsentrasi larutan dari 20 ppm dalam $50 \mathrm{~mL}$ menjadi 0.237 ppm sehingga mampu menggantikan adsorben karbon aktif yang sulit terdegradasi. Kondisi operasi optimum pada adsorpsi ini yaitu rasio massa cangkang telur dengan abu sekam padi sebesar 0.2:0.8 gram, waktu kontak 80 menit, dan pH 3 menghasilkan daya adsorpsi $98.817 \%$. Potensi kedua bahan tersebut sebagai bioadsorben didukung oleh adanya pori-pori dan gugus aktif.

Saran untuk penelitian selanjutnya yaitu mengkaji pengaruh konsentrasi zat warna metilen biru terhadap daya adsorpsi. Selain itu perlu dilakukan pengkajian mengenai proses aktivasi sampel adsorben menggunakan asam kuat dan basa kuat dengan variasi konsentrasi aktivator tersebut.

\section{Ucapan Terima Kasih}

Penulis mengucapkan terima kasih kepada laboran Teknik Kimia Fakultas Teknik Universitas Muhammadiyah Surakarta atas bimbingannya selama ini serta rekan-rekan mahasiswa Teknik Kimia Universitas Muhammadiyah Surakarta yang turut membantu dalam pelaksanaan penelitian.

\section{Daftar Pustaka}

1. Atmaji, P., Purwanto, W., Pramono, E. P., Daur ulang limbah hasil pewarnaan industri tekstil. J. Sains dan Teknol. Indones., 1(4): 9-15 (1999).

2. Selvam, K., Swaminathan, K. \& Chae, K. S., Decolourization of azo dyes and a dye industry effluent by a white rot fungus Thelephora sp. Bioresour. Technol., 88(2): 115-119 (2003).

3. Huda, T. \& Yulitaningtyas, T. K., Kajian Adsorpsi Methylene Blue Menggunakan Selulosa dari Alang-Alang. Indones. J. Chem. Anal., 1(1): 9-19 (2018).

4. Zille, A., Laccase Reactions for Textile Applications Andrea Zille Laccase Reactions for Textile Applications. Universidade do Minho, (2005). 
5. Laksono, E. W., Kajian penggunaan adsorben sebagai alternatif pengolahan limbah zat pewarna tekstil. in Prosiding Seminar Nasional FMIPA UNY, (2009).

6. Haryono, H., Faizal D, M., Liamita N, C. \& Rostika, A., Pengolahan Limbah Zat Warna Tekstil Terdispersi dengan Metode Elektroflotasi. EduChemia (Jurnal Kim. dan Pendidikan), 3(1): 94 (2018).

7. Zulfikar, M. A., Mariske, E. D. \& Djajanti, S. D., Adsorption of lignosulfonate compounds using powdered eggshell. Songklanakarin J. Sci. Technol., 34(3): 309-316 (2012).

8. Ehrampoush, M. H. \& Ghaneian, M. T., Equilibrium and Kinetics Study of Reactive Red 123 Dye Removal From Aqueous Solution By Adsorption on. Iranian J. Environ. Health Sci. Eng., 8(2): 101-108 (2011).

9. Tammi, T., Suaniti, N. \& Manurung, M., Variasi Konsentrasi Dan $\mathrm{Ph}$ Terhadap Kemampuan Kitosan Dalam Mengadsorpsi Metilen Biru. J. Kim., 7(1): 11-18 (2013).

10. Erawati, E. \& Helmy, E., pembuatan karbon aktif dari gergaji kayu jati (Tectona grandis $\mathrm{L}, \mathrm{f})$ (ukuran partikel dan jenis aktivator). Proceeding of The URECOL, 97-104 (2018).

11. Hajar, E. W. I., Sitorus, R. S., Mulianingtias, N. \& Welan, F. J., Efektivitas Adsorpsi Logam $\mathrm{Pb} 2+$ Dan Cd2+ Menggunakan Media Adsorben Cangkang Telur Ayam. Konversi, 5(1): 1-7 (2016).

12. Prima Astuti Handayani., Nurjanah, E. \& Rengga, W. D. P., Pemanfaatan Limbah Sekam Padi Menjadi Silika Gel Prima. 4(2): 55-59 (2015).

13. Wijayanti, I. E. \& Kurniawati, E. A., Studi Kinetika Adsorpsi Isoterm Persamaan Langmuir dan Freundlich pada Abu Gosok sebagai Adsorben. EduChemia (Jurnal Kim. dan Pendidikan), 4(2): 175 (2019).

14. Wardalia., Karakterisasi Pembuatan Adsorben Dari Sekam Padi Sebagai Pengadsorp Logam Timbal Pada Limbah Cair. J. Integr. Proses, 6(2): 83-88 (2016).

15. Haqiqi, E. R., Prosiding SEMNAS Kimia Unpad. Analisis FTIR (Fourier Transform InfraRed) Adsorben Zat Warna dari Limbah Cangkang Telur Ayam Dikombinasi Biomassa Sekam Padi, 17-25 (2018).

16. Pardede, E., Pemurnian Minyak Jelantah Menggunakan Adsorben Berbasis Cangkang Telur. J. Atmos., 1(1): 8-16 (2020).

17. Misfadhila, S., Azizah, Z., Rusdi. \& Chaniago, cynthia diane P., Pengaplikasian Cangkang Telur Dan Karbon Aktif Sebagai Adsorben Logam Timbal. Farm. Higea, 10(2): 1-8 (2018).

18. Padi, D. S., Sintesis Dan Karakterisasi Natrium Silikat ( Na2SiO3 ). 7: 90-97 (2015).

19. Nurlaili, T., Kurniasari, L. \& Ratnani, R. D., Pemanfaatan Limbah Cangkang Telur Ayam Sebagai Adsorben Zat Warna Methyl Orange Dalam Larutan. J. Inov. Tek. Kim., 2(2): (2017).

20. Kristiyani, D., Susatyo, E. B. \& Prasetya, A. T., Pemanfaatan zeolit abu sekam padi untuk menurunkan kadar ion $\mathrm{Pb} 2+$ pada air sumur. Indones. J. Chem. Sci., 1(1): (2012).

21. Riapanitra, A., Setyaningtyas, T. \& Riyani, K., Penentuan waktu kontak dan $\mathrm{pH}$ optimum penyerapan metilen biru menggunakan abu sekam padi. Molekul, 1(1): 41 (2006).

22. Hadayani, L., Riwayati, I. \& Ratnani, R., Adsorpsi Pewarna Metilen Biru Menggunakan Senyawa Xanthat Pulpa Kopi. J. Momentum UNWAHAS, 11(1): 114174 (2015). 